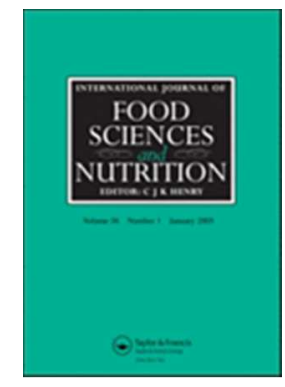

\title{
Supplementation of omega 3 fatty acids improves oxidative stress in activated BV2 microglial cell line
}

\begin{tabular}{|r|l|}
\hline Journal: & International Journal of Food Sciences and Nutrition \\
\hline Manuscript ID: & CIJF-2014-0600.R2 \\
\hline Danuscript Type: & Research Paper \\
\hline Complete List of Authors: & $\begin{array}{l}\text { Corsi, Lorenzo; University of Modena and Reggio Emilia, Life Sciences } \\
\text { Momo Dongmo, Bendjedith; University of Modena and Reggio Emilia, } \\
\text { Avallone, Rossella; University of Modena and Reggio Emilia, }\end{array}$ \\
\hline Keywords: & $\begin{array}{l}\text { supplement rich in PUFAs, peroxisome proliferator activated receptor, } \\
\text { Reactive oxygen species, nitric oxide }\end{array}$ \\
\hline \multicolumn{2}{|c}{} \\
\hline
\end{tabular}

SCHOLARONE $^{\text {m }}$

Manuscripts

URL: http://mc.manuscriptcentral.com/cijf Email: furio.brighenti@unipr.it 
Supplementation of omega 3 fatty acids improves oxidative stress in activated BV2 microglial cell line

\author{
Lorenzo Corsi, Bendjedith Momo Dongmo and Rossella Avallone* \\ Department of Life Sciences, Modena and Reggio Emilia University, \\ Via Campi 287, 41125 Modena, Italy
}

\begin{abstract}
*Corresponding Author: Rossella Avallone, Department of Life Sciences, Modena and Reggio Emilia University, via Campi 287, 41125 Modena, Italy, telephone: +39059 2055720, fax: +39 059 2055376, e-mail: rossella.avallone@unimore.it

Lorenzo, Corsi e-mail: 1orenzo.corsi@,unimore.it

Bendjedith, Momo Dongmo e-mail: momobendjedith@yahoo.fr
\end{abstract}

Keywords: supplement rich in PUFAs, peroxisome proliferator activated receptor, reactive oxygen species, nitric oxide. 


\section{Abstract}

Many reports have shown promising beneficial effects of long-chain polyunsaturated fatty acids (L-PUFAs) of the omega 3 series in several brain diseases. In the present study, we tested the hypothesis that a omega 3 fatty acids supplement reduced pro-inflammatory functions in vitro and in vivo.

We demonstrated that a supplement rich in PUFAs (SRP) increased cell viability in dosedependent manner suggesting its protective role against LPS-induced cell death in BV2 microglial cell line. In the same cultures, the supplement rich in PUFAs reduced the reactive oxygen species (ROS) and nitric oxide (NO) production. A most prominent target for ROS management is the family of peroxisome proliferator-activated receptors (PPARs). The cotreatment with SRP and LPS increased significantly the nuclear immunoreactivity of PPAR$\gamma$ when compared the LPS treatment alone. Moreover the chronic administration of the SRP in rats, increased the immunoreactivity of the PPAR- $\gamma 1$ protein confirming its potential neuroprotective effect. 


\section{Introduction}

Clinical and experimental studies document promising beneficial effects of long-chain polyunsatured fatty acids (L-PUFAs) of the omega 3 series in a number of systemic pathologies, from diabetes to cardiovascular diseases, as well as in several brain diseases (Calder, 2014). The omega 3 L-PUFAs, including eicosapentaenoic acid (EPA; 20:5) and docosahexaenoic acid (DHA; 22:6), derive from $\alpha$-linolenic acid (ALA; 18:3) via desaturation and elongation. ALA must be obtained from the diet, longer-chain omega 3 can be formed in man but biological conversion in slow and inefficient making diet an important source for these fatty acids as well. Both omega 3 and omega 6 L-PUFA are integral components of all cell membranes as part of the phospholipid bilayer. Within the phospholipid bilayer omega 3 L-PUFA and omega 6 L-PUFA can be interchanged, where incorporation into the membrane depends largely on PUFA availability both from diet and from chemical synthesis. Membrane composition, however, affects membrane function: omega 3 L-PUFAs increase membrane fluidity and permeability and are considered important in cell signaling and signal transduction.

DHA is the best represented omega 3 L-PUFA in the nervous system, where it contributes more than $30 \%$ to the total phospholipid amount of neuronal and retinal membranes (Niemoller \& Bazan, 2010). DHA is not merely a structural membrane component but also a modulator of crucial neurochemical processes, gene expression, synaptic plasticity, memory formation and intracellular calcium concentration (Sergeeva, Strokin \& Reiser, 2005; Crawford, 2006; McNamara, Carlson, 2006; Calder, 2009; Grintal et al., 2009). In addition, similarly to what was observed in a number of inflammatory based systemic disorders, DHA and its peroxidated (cyclopentenone neuroprostanes) or enzymatically generated (neuroprotectins and resolvins) derivatives display potent antiinflammatory functions in psychiatric disorders as well as in acute and chronic neurodegenerative conditions (Bazan, 2006; Musiek et al., 2008; Calder, 2009; Ebert et al., 2009; Groeger et al., 2010; Palacios-Pelaez, Lukiw, \& Bazan, 2010; Belayev et al., 2011). 
DHA exerts its effect also trough the interaction with the peroxisome proliferator-activated receptor (PPAR). During different neuropathological conditions the natural PPAR ligands are produced in high amounts. Besides activation of PPARs, these ligands have a variety of direct effects on neural cells, such as regulation of inflammation, calcium homeostasis and mitochondrial functions. Thus, PPARs and their ligands have well proven neuroprotective effects, and there are a number of reports concerning the PPAR involvement in regulation of ROS production. PPAR- $\gamma$ exists in two isoforms with no functional differences (PPAR- $\gamma 1$ and $\gamma 2$ ), and is highly expressed in adipose tissue, where it plays a central role in the regulation of adipogenesis (Willson, Lambert \& Kliewer, 2001). In addition, PPAR- $\gamma$ is found in cells of the immune system, including lymphocytes and macrophages. In peripheral monocytes, PPAR- $\gamma$ expression is induced during the process of extravasation from blood vessels into the tissues, and in the course of activation by pro-inflammatory stimuli. PPAR- $\gamma$ has been shown to be important for the differentiation of monocytes into macrophages and to act as a negative regulator of macrophage activation (Ricote et al., 1998a; Ricote, Li, Willsons, Kelly \& Glass, 1998b; Tontonoz, Nagy, Alvarez, Thomazy \& Evans, 1998 Daynes \& Jones, 2002). As for macrophages of peripheral tissues, PPAR $-\gamma$ regulates the activation of microglial cells, the main macrophage population found in brain parenchyma, suggesting that PPAR- $\gamma$ natural and synthetic agonists may control brain inflammation and that they could be exploited for the treatment of human brain diseases such as multiple sclerosis, Alzheimer's disease and Parkinson's disease.

The aim of the present study was to evaluate the potential neuroprotective effects of a supplement rich in PUFAs (SRP) in vitro in parallel to a modulation of PPAR- $\gamma$ in rat cerebral cortex.

\author{
Materials and methods \\ Cell cultures and treatments
}


The experiments were conducted on BV2 murine microglial cell line (ATCC, Teddington, UK). Cells were cultured in a humidified incubator at $37^{\circ} \mathrm{C}$ with $5 \% \mathrm{CO}_{2}$ in Dulbecco's modified Eagle's medium (DMEM; Sigma Aldrich SRL, Milan, Italy) containing 10\% heat-inactivated fetal bovine serum FBS, 2 mM L-glutamine (all from Invitrogen SRL, San Giuliano Milanese, Italy) with 100 units $/ \mathrm{mL}$ penicillin and $100 \mu \mathrm{g} / \mathrm{mL}$ streptomycin, $1 \mathrm{~mL}$ non-essential amino acids, $1 \mathrm{mM}$ sodium pyruvate (all from Sigma Aldrich SRL, Milan, Italy). The cultures were treated with a supplement rich in PUFAs (SRP) available on the market. The supplement rich in PUFAs, named Triolip® 1000 and provided by Sofar (Milan, Italy), derived from fish contains particularly high concentrations of EPA and DHA, respectively 40 and 20\%. The SRP is composed of $16.52 \%$ protein, $0 \%$ carbohydrates, 82.65 fats $(7.44 \%$ saturated, $9.918 \%$ monounsaturated, $65.293 \%$ polyunsaturated: $33.06 \%$ EPA, $16.53 \%$ DHA), $0.826 \%$ vitamin E. The fatty acids composition of SRP was verified by GC-MS analysis (Avallone et al., 2009). The use of advanced technology of extraction processes (multiple molecular distillation), which characterizes this formulation, ensures very low levels of pollutants such as dioxins, mercury and heavy metals normally present marine habitat. Moreover, the addition of vitamin E allows absolute protection of the active principles from peroxidative agents. In the supplement rich in PUFAs, EPA and DHA are present in the form of triglycerides. SRP stock solution was dissolved in dimethyl sulfoxide (DMSO Sigma Aldrich SRL, Milan, Italy) and then diluted at final concentrations ranging from $0.5 \mu \mathrm{g} / \mathrm{mL}$ (corresponding to 0,5 $\mu \mathrm{M}$ of EPA and $0,25 \mu \mathrm{M}$ of DHA) to $40 \mu \mathrm{g} / \mathrm{mL}$ (corresponding to $40 \mu \mathrm{M}$ of EPA and $20 \mu \mathrm{M}$ of DHA) in DMEM. The final concentration of DMSO in the medium was less than $0.05 \%$ (vol/vol). Animals and diets

Six-week-old male Sprague-Dawley rats (200-250 g) (Harlan Italy, Udine, Italy) were used throughout the experiment in a controlled environment (air-conditioned room at $22 \pm 1 \circ \mathrm{C}$ and $60 \%$ humidity) maintained under a $12 \mathrm{~h}$ light/dark cycle. Rats had free access to water and food, a standard pellet containing $188 \mathrm{~g} \mathrm{~kg}-1$ crude proteins, $60 \mathrm{~g} \mathrm{~kg}-1$ crude fats, $38 \mathrm{~g} \mathrm{~kg}-1$ fibre and 500 $\mathrm{g} \mathrm{kg}-1$ carbohydrates. The animals were randomly assigned to one of two groups (olive oil 
supplemented named olive oil fed group and supplement rich in PUFAs named SRP group) and treated for 30 days by oral gavage as follows: the olive oil fed group $(n=10)$ and the SRP group $(n$ $=10$ ) received respectively $2 \mathrm{~g}$ of extra virgin olive oil and $2 \mathrm{~g} / \mathrm{rat} / \mathrm{day}$ of the supplement rich in PUFAs (Rustichelli et al, 2012). The use of extra virgin olive oil in the olive oil fed group is necessary to match the caloric content due to fatty acids supplementation and to remove the weight gain influence. Animals were sacrificed $24 \mathrm{~h}$ after the last treatment. The cerebral cortices were collected, washed free from blood in ice-cold normal saline solution, dried with blotting paper and then stored at $-80{ }^{\circ} \mathrm{C}$ until analysis. All procedures were performed in accordance with the guidelines of the National (DL no. 116/1992) and European legislation (EEC no. 86/609) and guidelines of the National Institutes of Health on the use and care of laboratory animals.

\section{Cell viability test}

Cytotoxicity assays were performed with the CellTiter-96® AQueousMTS Proliferation Assay (Promega, Milan, Italy) in 96 well plates. BV2 microglial cells were seeded at a density of 10,000 cells per well. Cytotoxicity was measured by adding $20 \mu \mathrm{L}$ MTS (3-[4,5-dimethylthiazol-2-yl]-5-[3carboxymethoxyphenyl]-2-[4-sulfophenyl]-2H-tetrazolium, inner salt] $24 \mathrm{~h}$ after treatments according to the manufacturer's protocol. Cells were treated with $0.05,0.5,5,10,20 \mu \mathrm{g} / \mathrm{mL}$ of the supplement rich in PUFAs in presence or absence of lipopolysaccharide (LPS) (Sigma, Milan, Italy) at the concentration of $1 \mu \mathrm{g} / \mathrm{mL}$. The microplates were incubated at $37{ }^{\circ} \mathrm{C}$ for up to 2 hours and the absorbance was detected at $492 \mathrm{~nm}$ using a spectrophotometer (Labsystem Multiscan ${ }^{\circledR}$ MCC/340, Finland).

ROS assay

To examined the effect of the supplement rich in PUFAs on reactive oxygen species (ROS) production in LPS-stimulated BV2 microglial cell lines, the fluorogenic probes CellROX ${ }^{\circledR}$ Green Flow Cytometry Assay Kit (Life Technologies, Milan, Italy), designed to reliably measure ROS in live cells, have been used. The fluorescence resulting from CellROX ${ }^{\circledR}$ Oxidative Stress Reagents was measured using a microplate fluorometer (Fluoroskan Ascent FL, Biorad, Milan, Italy). 
Briefly, BV2 microglial cells were seeded at concentration of 15000 cells/well and stimulated for $6 \mathrm{~h}$ with LPS $(1 \mu \mathrm{g} / \mathrm{mL})$ in the absence or presence of different concentrations of SRP. Successively, $10 \mu \mathrm{L}$ of "CellROX Green" solution were added in each well 30 minutes before the end of treatment at the concentration of $5 \mu \mathrm{M}$ and the fluorescence were measure using "fluorskan Ascent FL".

NO assay

Griess reagent kit (Molecular Probe-Life Technologies, Milan, Italy) was used to measure the production of nitric oxide (NO) present in the supernatant of BV2 microglial cells treated with LPS $(1 \mu \mathrm{g} / \mathrm{mL})$ for 24 hours (Ajmone-Cat, 2012), with increasing concentrations of SRP $(0.5-10 \mu \mathrm{g} / \mathrm{mL})$ according to the manufacturer's instructions. Briefly, 10000 cells were seeded and incubated for the different compounds. After $24 \mathrm{~h} 85 \mu \mathrm{L}$ of buffer assay was added to each sample, $5 \mu \mathrm{L}$ of nitric reductase, $5 \mu \mathrm{L}$ of enzyme cofactor were successively added to each well and incubated for 1 hour at room temperature. $5 \mu \mathrm{L}$ of promoter was added to each well successively incubated for 10 minutes. The samples were mixed with an equal volume $(50 \mu \mathrm{L})$ of freshly prepared Griess reagent, and the absorbance was measured at $540 \mathrm{~nm}$ using a spectrophotometer (Labsystem Multiscan ${ }^{\circledR}$ MCC/340, Finland).

\section{Immunoblotting}

To examine the expression of $\mathrm{PPAR} \gamma$ protein in the BV2 microglial cells and cerebral cortex of rats, standard western blot analysis was performed. Cells treated with LPS $(1 \mu \mathrm{g} / \mathrm{mL})$, SRP $(10 \mu \mathrm{g} / \mathrm{mL})$, LPS in presence of the supplement rich in PUFAs $(10 \mu \mathrm{g} / \mathrm{mL})$ or not-treated cells were lysed in RIPA buffer (50 mM Tris- $\mathrm{HCl} \mathrm{pH} 7.4,150 \mathrm{mM} \mathrm{NaCl}, 1 \% \mathrm{Na}$ deoxycolate, 1\% Triton X-100, 2 mM PMSF) (Sigma, Milan, Italy). Nuclei extraction from BV2 microglial cells was performed using a density barrier system. Cells were scraped from $150 \mathrm{~mm}$ dishes into $3 \mathrm{~mL}$ Tris phosphate buffered saline (20 mM Tris- $\mathrm{HCl}, 0.5 \mathrm{M} \mathrm{NaCl}$ and $0.05 \%$ Tween 20) (TBST) and centrifuged at $36000 \mathrm{~g}$ for $10 \mathrm{~min}$. Cell pellets were resuspended in TBST and homogenized with potter. The 
homogenate was adjusted to $25 \%(\mathrm{w} / \mathrm{v})$ iodixanol (Sigma, Milan, Italy) and layer over a barrier of $30 \%(\mathrm{w} / \mathrm{v})$ iodixanol and then centrifuged at $10000 \mathrm{~g}$ for $20 \mathrm{~min}$. The obtained pellet was enriched in nuclei. The cerebral cortex was homogenized with RIPA and centrifuged at $12000 \mathrm{~g}$ for 10 minutes at $4{ }^{\circ} \mathrm{C}$ and the supernatants were collected. The proteins quantification was performed using Bradford colorimetric method Commassie (Pierce, Rockford, USA) according to the manufacturer's protocol. Equal amount of proteins, ranging from 0.5 to $10 \mu \mathrm{g} / \mu \mathrm{l}$, were separated through 12\% SDS-PAGE mini gel and electrophoretically transferred onto nitrocellulose membrane all purchased from Invitrogen (Life Technology, Milan, Italy). The membrane was blocked in TBST containing $10 \%$ milk overnight at $4{ }^{\circ} \mathrm{C}$ at room temperature (RT) and incubated with primary antibody anti-PPAR $\gamma(1: 500)$ at RT for 3 hours (Cayman Chemical Company, Ann Arbor, USA). Membrane was then washed 5 times in TBST for 10 min. each time, incubated for $1 \mathrm{~h}$ with HRPconjugated anti-rabbit secondary antibody (Santa Cruz, Dallas, USA), and visualized using chemiluminescence method (Amersham, GE Healthcare Europe GmbH, Milan, Italy). The membrane was successively stripped and incubated with a primary antibodies anti- $\beta$-actin (1:5000) or anti-lamin (1:1000) followed by incubation with HRP-conjugated anti-mouse secondary antibody respectively (Millipore, Darmstadt, Germany). The immune-complexes were visualized using chemiluminescent method, and analyzed using a BioRad GS 690 Imaging densitometer with molecular analysis software (Life science, Milan, Italy).

Statistical Analysis

The results are expressed as mean \pm standard deviation (SD) of at least three independent experiments done in quadruplicate. Comparison of multiple means was performed using one-way ANOVA with the Tukey's and Dunnett's as post hoc test and t-test was performed to compare two groups, as indicated in the figures (Graph Pad Inc., La Jolla, USA). Mean values were considered significantly different when $\mathrm{P}<0.05$ as outlined in the text. 


\section{Results}

Supplement rich in PUFAs protects BV2 microglial cells LPS-mediated cytotoxicity

To investigate the potential cytotoxic effect of the supplement rich in PUFAs, BV2 microglial cells were treated with different concentrations of SRP. As shown in Fig. 1A, no cytotoxic effects were observed following treatment of BV2 microglial cells with $0.5-20 \mu \mathrm{g} / \mathrm{mL}$ of SRP for $24 \mathrm{~h}$. Concentration of $40 \mu \mathrm{g} / \mathrm{mL}$ produced cytotoxic effects and then it was excluded from further experiments. Furthermore, to determine whether treatment with SRP protects against the cell death induced by LPS, BV2 microglial cells were treated with different concentrations of SRP in presence or not of $1 \mu \mathrm{g} / \mathrm{mL}$ LPS. As shown in Fig. 1B, the co-treatment of SRP and LPS on BV2 cells increased significantly the conversion of MTS in formazan product compared to values obtained in LPS-stimulated cultures alone. Indeed, the treatment with SRP increased significantly BV2 cell viability compared to LPS-treated cells, restoring the values to those of the control.

\section{Supplement rich in PUFAs inhibits ROS and NO production in activated BV2 microglial cells}

To study the ability of the SRP to modulate the microglial activation, we examined the effects of this supplement at different concentrations on LPS-induced ROS and NO production in BV2 cell line. We exposed microglial cultures to increasing concentrations of SRP, in the absence or in the presence of LPS and measured the ROS production and the levels of nitrite, a stable end product of NO accumulated in the medium. Incubation with LPS for $6 \mathrm{~h}$ significantly increased the ROS production in BV2 cells, when compared to that in untreated cells. However, co-treatment with the SRP, significantly prevented the increase of ROS production in BV-2 cells in a dose dependent manner (Fig. 2). The SRP alone at the higher concentration tested did not alter ROS production in BV-2 cells (data not shown). Similarly, SRP treatment was able to modulate the LPS-related NO production in BV2 cells. The amount of nitrite was measured after $24 \mathrm{~h}$ of treatment with SRP in presence or not of LPS. In the absence of LPS, basal nitrite production was close to the detection limit of the assay and remained undetectable in the presence of SRP (data not shown). However, SRP significantly reduced, in a dose-dependent manner, the LPS-induced nitrite accumulation in 
BV2 microglia cells as shown in Fig. 3.

Effect of SRP on PPAR $\gamma$ nuclear translocation and PPAR expression in activated BV2 microglia cells

The activation of PPAR- $\gamma$ nuclear receptors, through ligands agonist such as DHA (Yu et al., 1995; Kliewer et al., 1997), has been proposed as anti-inflammatory machinery in the central nervous system (Combs, Johnson, Karlo, Cannady \& Landreth, 2000; Niemoller \& Bazan, 2010). To verify the hypothesis that the SRP could induce PPAR- $\gamma$ activation in BV2 microglia cells, we analyzed PPAR- $\gamma$ protein expression and its nuclear translocation following exposure to $10 \mu \mathrm{g} / \mathrm{mL}$ of the SRP in presence or not of LPS. Western blot analysis showed that the treatment with SRP did not induce an increase of PPAR $\gamma$ protein in the total cell lysate of BV2 microglia cells. Indeed, the immunoreactivity of the treated cells did not change compared to control, suggesting that the expression of PPAR $\gamma$ is not affected by SRP and/or LPS (Fig. 4 C, D). However, as shown in Fig. 4A, an increase in immunoreactivity intensity was observed in nuclear subcellular fraction of cultures exposed to SRP for 90 min. compared with untreated cells, confirming the data by AjmoneCat et al., 2012. Conversely, LPS was able to inhibit the PPAR $\gamma$ nuclear translocation resulted in immunoreactivity barely detectable (Fig. 4A). SRP treatment was able to counteract the LPS effect on the translocation of PPAR $\gamma$. Indeed, the co-treatment with SRP and LPS increased significantly the nuclear immunoreactivity of PPAR- $\gamma$ when compared the LPS treatment alone (Fig. 4B). However, immmnoblotting analysis on BV2 total cell lysate did not show any difference between control and treated cells (data not shown).

Supplement rich in PUFAs modulates PPARs protein expression in rat cerebral cortex

In order to evaluate the effect of SRP on PPAR $\gamma$ protein expression in physiological condition, Sprague Dawley male rat were chronically treated with $2 \mathrm{~g} / \mathrm{rat} /$ day of SRP and Western blot analysis was performed on crude tissue homogenates with specific antibodies. As shown in Fig. 5A, immunochemical results showed a significant modulation of PPAR $\gamma 1$ proteins expression in rat 
cerebral cortex. Western blot analysis of PPAR $\gamma$ protein, revealed the presence of a $57 \mathrm{kDa}$ and a 52 $\mathrm{kDa}$ molecular mass level proteins corresponding to PPAR $\gamma 2$ and PPAR $\gamma 1$ respectively. As shown in Figure 5 while the intensity of PPAR $\gamma 2$ immunosignal was not affected by the SRP treatment, the PPAR $\gamma 1$ protein significantly increased its immunoreactivity in treated samples compared to the not-treated ones (Fig. 5B).

\section{Discussion}

PUFAs are essential for normal human growth; however, only minor quantities of the beneficial omega 3 PUFAs eicosapentaenoic acid (EPA) and docosahexaenoic acid (DHA) are synthesized by human metabolism. A small amount of EPA and DHA (less than 5\%) can be converted through enzymatic reactions by ALA in the human body (Brenna, 2002). So the use of nutraceutical and functional foods containing omega 3 PUFAs has become a topic of great interest for the health of the world population, due to their reported and accepted beneficial effects.

The present study tested the hypothesis that a supplement rich in PUFAs containing high concentrations of EPA and DHA, reduced LPS-induced microglial pro-inflammatory functions.

In spite of its defensive nature, microglial activation may contribute to neuronal functional impairment when inappropriately triggered or deployed to excess. It is now clear that the process of microglia activation is tightly controlled by soluble factors and cell-to-cell interactions, and that the failure of such control may lead to severe neuronal impairment (Polazzi \& Contestabile, 2002; De Simone, Ajmone-Cat \& Minghetti, 2004). In this context omega 3 PUFAs EPA and DHA might exert their potential beneficial effects by protecting and/or regulating the microglia functions. Although in the supplement rich in PUFAs used in these experiments it's impossible to discriminate the effects of DHA and those of EPA as DHA, our results demonstrated that SRP increased BV2 cell viability in a dose-dependent manner suggesting its protective role against LPS-induced cell death in BV2 microglial cell line. However, the role of microglia appears particularly important in 
chronic degenerative diseases, in which activated microglia sustains a local inflammatory response (Perry, Bolton, Anthony \& Betmouni, 1998) trough oxidative stress activation and cytokines release (Wang, Wen, Huang, Chen $\& \mathrm{Ku}, 2006$ ). Thus, the identification of compounds and molecular mechanisms that prevent glial reaction, in particular microglial activation, is crucial for the development of therapeutic agents for inflammatory brain diseases.

Oxidative stress is responsible for redox regulation involving not only ROS but also NO production. Both ROS and reactive nitrogen species can oxidize and damage macromolecules, such as DNA, proteins, and lipids, culminating in neurodegeneration in the central nervous system (Wang, Wen, Huang, Chen \& Ku, 2006). Noteworthy was the evidence that, in the BV2 microglial cell line, a supplement rich in PUFAs strongly reduced the ROS and NO production consistently with reports on peripheral macrophages and microglial cell lines (Khair-El-Din et al., 1996; De Smedt-Peyrusse et al., 2008; Calder, 2009). A most prominent target for ROS management is the peroxisome proliferator-activated receptors family (PPARs). In our study the co-treatment with a supplement rich in PUFAs and LPS increased significantly the nuclear immunoreactivity of PPAR- $\gamma$ when compared the LPS treatment alone but not in the total cell lysate, suggesting that SRP might act as activator of nuclear PPAR- $\gamma$ rather then a modulator of protein expression in BV2 cell line. As a further contributing mechanism, our data suggest that a supplement rich in PUFAs induces the nuclear translocation of the nuclear receptor PPAR- $\gamma$, a potent modulator of microglial activation. PPAR- $\gamma$ belongs to a broad family of agonist-dependent transcription factors that modulate the expression of several genes involved in metabolic, developmental, and immune processes (Bernardo \& Minghetti, 2008). In particular, in LPS or IFN- $\gamma$-stimulated microglia, PPAR- $\gamma$ activation decreases the expression of proinflammatory mediators, and PPAR- $\gamma$ agonists have been proposed for treating inflammatory brain diseases (Bernardo \& Minghetti, 2006). The inhibitory activity of the supplement rich in PUFAs on observed NO production could be interpreted as an effect of PPAR $\gamma$ activation. Our observations are in line with the current literature that lists PPAR- $\gamma$ 
among the molecular targets of DHA and other PUFAs in adipocytes, dendritic cells, and microglia (Yu et al., 1995; Kliewer et al., 1997; Combs, Johnson, Karlo, Cannady \& Landreth, 2000; Niemoller \& Bazan, 2010). It is well known, however, that PPAR agonists may have also PPARindependent effect. We cannot rule out the contribution to the observed effects of biologically active DHA derivatives, e.g., resolvins and neuroprotectins, enzymatic oxygenated products isolated and characterized as potent proresolving mediators.

Interesting was the results obtained in animals fed with the a supplement rich in PUFAs. Indeed the chronic administration of the SRP increased the immunoreactivity of the PPAR $\gamma 1$ protein, whereas the PPAR $\gamma 2$ protein expression was unaffected. This result suggests that omega 3 PUFA might act in a preventive fashion in vivo exerting a potential neuroprotective effect. Indeed, the chronic use of the SRP through PPAR $\gamma 1$ activation has a potential anti-inflammatory effect. It was demonstrated, in fact, that PPARs may reduce ROS levels via induction of ROS-degrading pathways, such as catalase, superoxide dismutase, glutathione peroxidase, cytochrome c oxidase, gammaglutamylcysteine ligase and glutathione. Another way for PPAR-dependent downregulation of ROS levels is the ability to reduce levels of ROS-producing pathways, such as NO synthase, myeloperoxidase, NAPH oxidase, cofactor tetrahydrobiopterin and argininosuccinate lyase. The PPAR receptors may induce ROS levels via upregulation of peroxisomal oxidation and, especially, by induction of Acyl-CoA oxidases (Aleshin \& Reiser, 2013). Thus, the PPAR-dependent positive and negative ROS regulation is important to maintain balanced ROS levels.

Our results showed a different pattern of PPAR $\gamma$ protein expression between in vivo and in vitro model. This discrepancy could be due to the different substrate used. Indeed in the cerebral tissues there is a wide range of cell population, which in turn might express different isoforms of the mentioned protein, compared to the microglia alone. Another speculation could be that the BV2 mainly express PPAR- $\gamma 2$, also in vivo their expression was not affected by SRP, and that after activation with the SRP the receptors translocate to the nucleus exerting neuroprotective functions. 


\section{Conclusion}

Finally, our data confirm that the activation of PPAR by a supplement rich in PUFAs will be a powerful therapeutic tool for normalization of ROS levels in a wide range of neuropathological diseases. In the supplement rich in PUFAs used in this study, EPA and DHA are present in the form of triglycerides, micronutrients naturally recognized by the body, to guarantee high digestibility and absorption by the intestinal mucosa. This allows to reduce the daily administration of the product, compared to the omega 3 in the form of ethyl esters. Oily fish intake amongst many populations is low and infrequent. An alternative source of $\omega 3$ PUFAs which can be taken regularly is supplements such as fish oil. Most fish oils contain about 30\% of EPA and DHA. Thus, a single one gram capsule of fish oil can provide about $300 \mathrm{mg}$ EPA plus DHA. The supplement rich in PUFAs used in the present study is a highly concentrated, pharmaceutical preparation of omega 3 PUFAs containing about $60 \%$ EPA plus DHA. Our results support the notion that dietary fish oil supplementation may enhance resistance to free radical attack and also that $\omega 3$ fatty acids may be effective dietary supplement in the management of various diseases in which oxidant/antioxidant balance is disturbed as in neuroinflammation.

\section{Acknowledgments}

We thank Sofar, Milan who provided the dietetic oil and Mario Baraldi Foundation for Sciences for financial support.

\section{Declaration of Interest}

Herein Prof. Lorenzo Corsi discloses any actual or potential conflict of interest including any financial, personal or other relationships with other people or organizations within three years of 
beginning the submitted work that could inappropriately influence, or be perceived to influence, their work. 


\section{References}

Ajmone-Cat M, Lavinia Salvatori M, De Simone R, Mancini M, Biagioni S, Bernardo A Cacci E, Minghetti L. (2012). Docosahexaenoic acid modulates inflammatory and antineurogenic functions of activated microglial cells. J Neurosci Res 90:575-587.

Aleshin S, Reiser G. (2013). Role of the peroxisome proliferator-activated receptors (PPAR)- $\alpha, \beta / \delta$ and $\gamma$ triad in regulation of reactive oxygen species signaling in brain. Biol Chem 394:1553-1570.

Avallone R, Rustichelli C, Campioli E,. Notarangelo FMP, Braghiroli D, Baraldi M (2009). AlphaLinolenic acid and Linoleic acid in serum and tissues after flaxseed (Linum usitatissimum) oil in vivo administration. J Food Lipids 16: 287-296.

Bazan NG. (2006). The onset of brain injury and neurodegeneration triggers the synthesis of docosanoid neuroprotective signaling. Cell Mol Neurobiol 26:901-913.

Belayev L, Khoutorova L, Atkins KD, Eady TN, Hong S, Lu Y, Obenaus A, Bazan NG. (2011). Docosahexaenoic Acid therapy of experimental ischemic stroke. Transl Stroke Res 2:33-41.

Bernardo A, Levi G, Minghetti L. (2000). Role of the peroxisome proliferator-activated receptorgamma (PPAR-gamma) and its natural ligand 15-deoxy-Delta12, 14-prostaglandin $\mathrm{J} 2$ in the regulation of microglial functions. Eur J Neurosci 12:2215-2223.

Bernardo A, Minghetti L. (2006). PPAR-gamma agonists as regulators of microglial activation and brain inflammation. Curr Pharm Des 12:93-109.

Bernardo A, Minghetti L. (2008). Regulation of Glial Cell Functions by PPAR-gamma Natural and Synthetic Agonists. PPAR Res 2008:864140.

Brenna JT. (2002). Efficiency of conversion of alpha-linolenic acid to long chain n-3 fatty acids in man Curr Opin Clin Nutr Metab Care 5:127-132. 
Calder PC. (2009). Polyunsaturated fatty acids and inflammatory processes: New twists in an old tale. Biochimie 91:791-795.

Calder PC. (2014). Marine omega-3 fatty acids and inflammatory processes: Effects, mechanisms and clinical relevance. Biochimica et Biophysica Acta, in press.

Combs CK, Johnson DE, Karlo JC, Cannady SB, Landreth GE. (2000). Inflammatory mechanisms in Alzheimer's disease: inhibition of beta-amyloid-stimulated proinflammatory responses and neurotoxicity by PPARgamma agonists. J Neurosci Off J Soc Neurosci 20:558-567.

Crawford MA. (2006). Docosahexaenoic acid in neural signaling systems. Nutr. Health 18:263276.

Daynes RA, Jones DC. (2002). Emerging roles of PPARs in inflammation and immunity. Nat Rev Immunol 2:748-759.

De Simone R, Ajmone-Cat MA, Minghetti L. (2004). Atypical antiinflammatory activation of microglia induced by apoptotic neurons: possible role of phosphatidylserine-phosphatidylserine receptor interaction. Mol Neurobiol 29:197-212.

De Smedt-Peyrusse V, Sargueil F, Moranis A, Harizi H, Mongrand S, Layé S. (2008). Docosahexaenoic acid prevents lipopolysaccharide-induced cytokine production in microglial cells by inhibiting lipopolysaccharide receptor presentation but not its membrane subdomain localization. J Neurochem 105:296-307.

Ebert S, Weigelt K, Walczak Y, Drobnik W, Mauerer R, Hume DA, Weber BHF, Langmann T. (2009). Docosahexaenoic acid attenuates microglial activation and delays early retinal degeneration. J Neurochem 110:1863-1875. 
Groeger AL, Cipollina C, Cole MP, Woodcock SR, Bonacci G, Rudolph TK, Rudolph V, Freeman BA, Schopfer FJ. (2010). Cyclooxygenase-2 generates anti-inflammatory mediators from omega-3 fatty acids. Nat Chem Biol 6:433-441.

Khair-El-Din T, Sicher SC, Vazquez MA, Chung GW, Stallworth KA, Kitamura K, Miller RT, Lu CY. (1996). Transcription of the murine iNOS gene is inhibited by docosahexaenoic acid, a major constituent of fetal and neonatal sera as well as fish oils. J Exp Med 183:1241-1246.

Kliewer SA, Sundseth SS, Jones SA, Brown PJ, Wisely GB, Koble CS, Devchand P, Wahli W, Willson,TM, Lenhard JM, Lehmann JM. (1997). Fatty acids and eicosanoids regulate gene expression through direct interactions with peroxisome proliferator-activated receptors alpha and gamma. Proc Natl Acad Sci USA 94:4318-4323.

McNamara RK, Carlson SE. (2006). Role of omega-3 fatty acids in brain development and function: potential implications for the pathogenesis and prevention of psychopathology. Prostaglandins Leukot Essent Fatty Acids 75:329-349.

Musiek ES, Brooks JD, Joo M, Brunoldi E, Porta A, Zanoni G, Vidari G, Blackwell TS, Montine TJ, Milne GL, McLaughlin B, Morrow JD. (2008). Electrophilic cyclopentenone neuroprostanes are anti-inflammatory mediators formed from the peroxidation of the omega-3 polyunsaturated fatty acid docosahexaenoic acid. J Biol Chem 283:19927-19935.

Niemoller TD, Bazan NG. (2010). Docosahexaenoic acid neurolipidomics. Prostaglandins Other Lipid Mediat 91:85-89.

Palacios-Pelaez R, Lukiw WJ, Bazan NG. (2010). Omega-3 essential fatty acids modulate initiation and progression of neurodegenerative disease. Mol Neurobiol 41:367-374.

Perry VH, Bolton SJ, Anthony DC, Betmouni S. (1998). The contribution of inflammation to acute and chronic neurodegeneration. Res Immunol 149:721-725. 
Polazzi E, Contestabile A. (2002). Reciprocal interactions between microglia and neurons: from survival to neuropathology. Rev Neurosci 13:221-242.

Ricote M, Huang J, Fajas L, Li A, Welch J, Najib J, Witztum JL, Auwerx J, Palinski W, Glass CK (1998). Expression of the peroxisome proliferator-activated receptor gamma (PPARgamma) in human atherosclerosis and regulation in macrophages by colony stimulating factors and oxidized low density lipoprotein. Proc Natl Acad Sci USA 95:7614-7619.

Ricote M, Li AC, Willson TM, Kelly CJ, Glass CK. (1998). The peroxisome proliferator-activated receptor-gamma is a negative regulator of macrophage activation. Nature 391:79-82.

Rustichelli C, Avallone R, Campioli E, Braghiroli D, Baraldi M (2012). Polyunsaturated fatty acid levels in rat tissues after chronic treatment with dietetic oils. J Sci Food Agric 92: 239-245.

Sergeeva M, Strokin M, Reiser G. (2005). Regulation of intracellular calcium levels by polyunsaturated fatty acids, arachidonic acid and docosahexaenoic acid, in astrocytes: possible involvement of phospholipase A2. Reprod Nutr Dev 45:633-646.

Tontonoz P, Nagy L, Alvarez JG, Thomazy VA, Evans RM. (1998). PPARgamma promotes monocyte/macrophage differentiation and uptake of oxidized LDL. Cell 93:241-252.

Wang JY, Wen LL, Huang YN, Chen YT, Ku MC. (2006). Dual effects of antioxidants in neurodegeneration: direct neuroprotection against oxidative stress and indirect protection via suppression of glia-mediated inflammation. Curr Pharm Des 12:3521-3533.

Willson TM, Lambert MH, Kliewer SA. (2001). Peroxisome proliferator-activated receptor gamma and metabolic disease. Annu Rev Biochem 70:341-367.

Yu K, Bayona W, Kallen CB, Harding HP, Ravera CP, McMahon G, Brown M, Lazar MA. (1995). Differential activation of peroxisome proliferator-activated receptors by eicosanoids. J Biol Chem 270:23975-23983. 


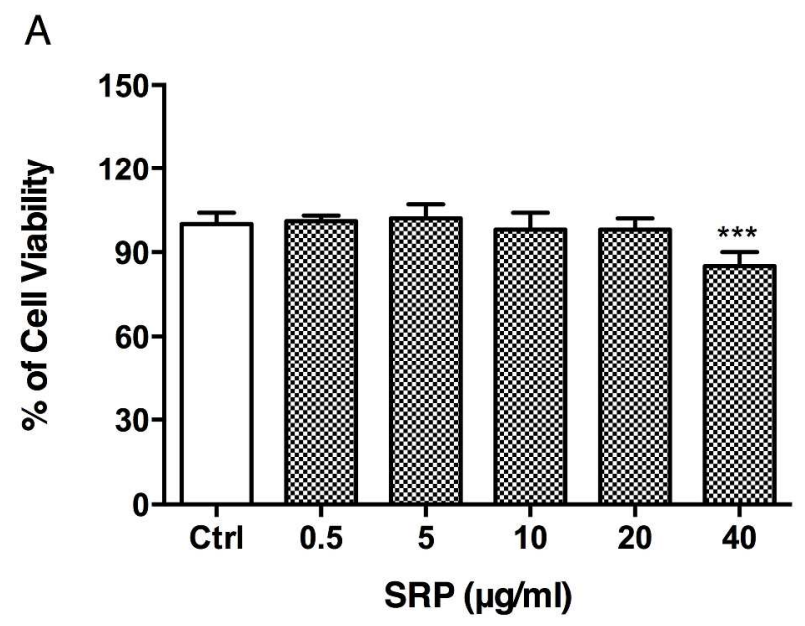

B

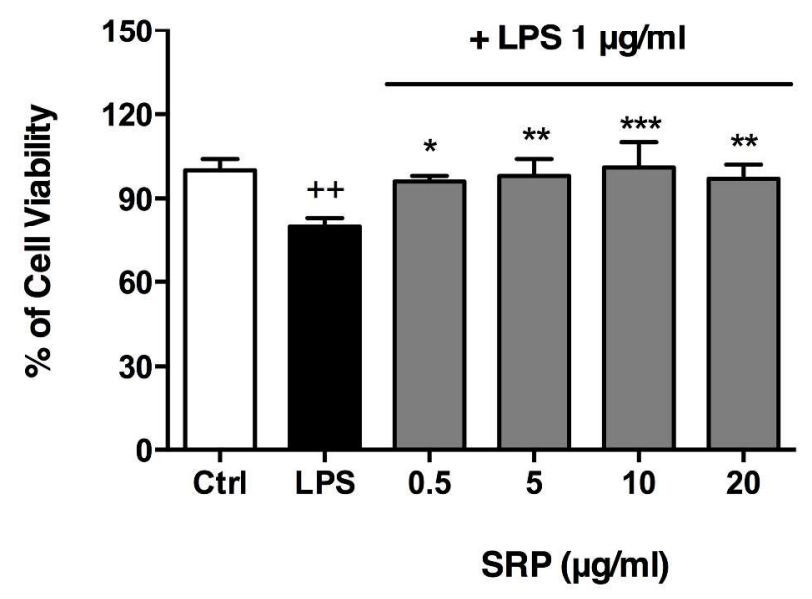

Cell viability of BV2 microglial cell line after exposure to different concentrations of supplement rich in PUFAs (SRP) and LPS. (A) Effects of $24 \mathrm{~h}$ exposure to different concentrations of SRP on BV2 microglial cell line monitored by the MTS assay. Only the highest concentration of SRP decreased significantly the BV2 cell viability compared to not-treated cells: $* * * P<0.001$ vs Ctrl using one-way ANOVA with Dunnett's as post test. (B) Effects of the supplement rich in PUFAs (SRP) on LPS-induced cytotoxicity on BV2 microglial cell line $(++\mathrm{P}<0.01 \mathrm{vs} \mathrm{Ctrl}$, using one-way ANOVA with Tukey's as post test). SRP significantly decreased the BV2-cytotoxicyty elicited by LPS at all the concentrations tested. Values represent means \pm SD from three different experiments $(n=6) . * P<0.05, * * P<0.01, * * * P<0.001$ vs LPS using one-way ANOVA with Tukey's as post test.

$196 \times 353 \mathrm{~mm}(300 \times 300$ DPI) 


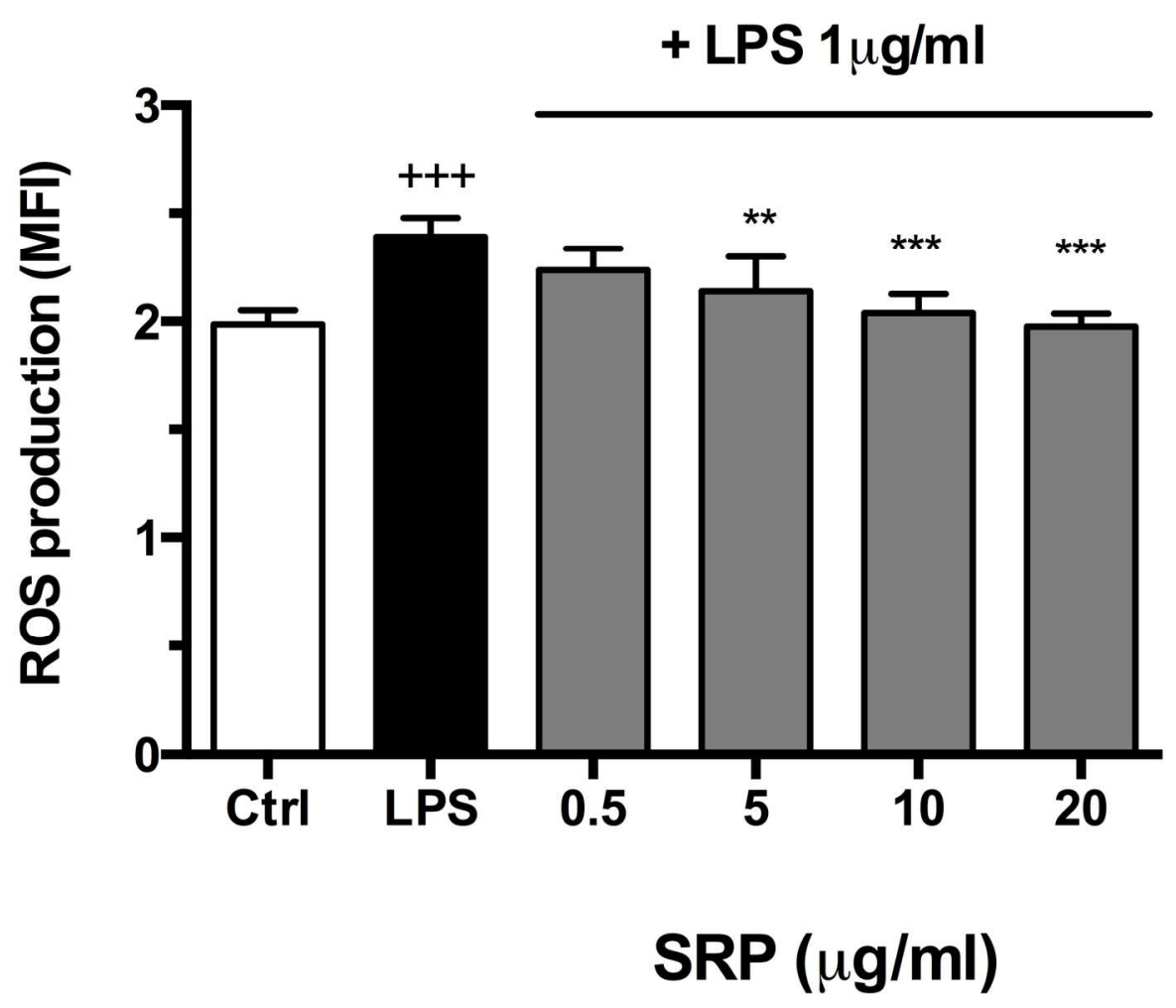

ROS formation in LPS-activated BV2 microglial cell line as measured by Cell-ROX assay after $24 \mathrm{~h}$ of exposure in presence or not to different concentrations of supplement rich in PUFAs (SRP). Results are expressed as median fluorescence intensity (MFI). LPS treatment significantly increased the MFI compared to not-treated cells ( $+++P<0.001$ vs Ctrl, using one-way ANOVA with Tukey's as post test). Co-treatment of BV2 microglial cells with LPS and different concentrations of SRP significantly reduced the level of ROS in LPS-activated BV2 cell line. Data shown are means \pm SD of three independent experiments $(n=6)$. **P< 0.01 , and $* * * P<0.001$ vs LPS using one-way ANOVA with Tukey's as post test. $80 \times 64 \mathrm{~mm}(600 \times 600 \mathrm{DPI})$ 


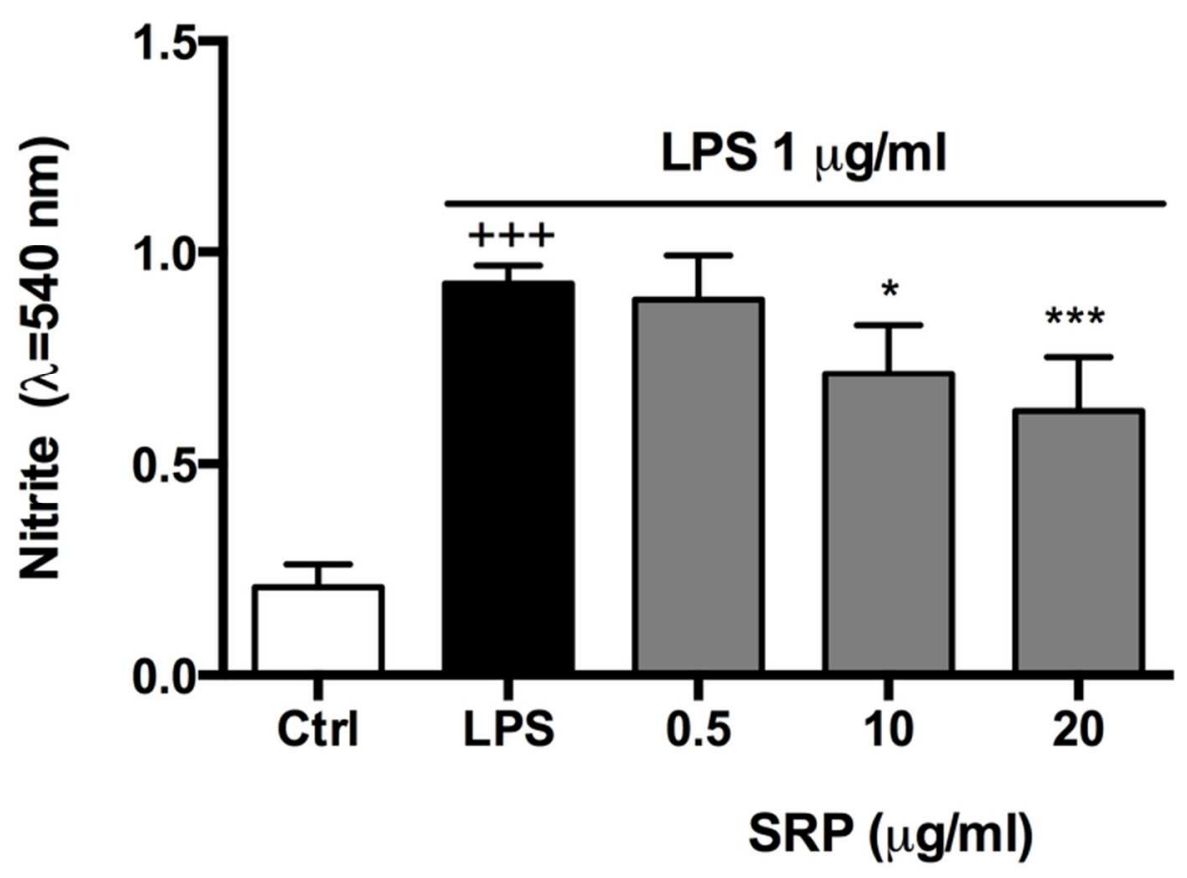

Effect of supplement rich in PUFAs (SRP) on LPS-activated BV2 microglial cell line nitrite levels as measured by the absorbance at $\lambda 540 \mathrm{~nm}$. BV2 microglial cell line treatment with LPS of for $24 \mathrm{~h}$ resulted in a significant increase of nitrite levels compared to the not-treated cells referred as control $(+++P<0.001$ vs Ctrl, using one-way ANOVA with Tukey's as post test). Co-administration of LPS and SRP at different concentrations on BV2 microglial cells significantly reduced LPS-activated BV2 nitrite levels: ${ }^{*} \mathrm{P}<$ $0.05, * * * P<0.001$ vs LPS using one-way ANOVA with Tukey's as post test. Data shown are means \pm SD of three independent experiments $(n=5)$. $72 \times 50 \mathrm{~mm}(300 \times 300 \mathrm{DPI})$ 
A

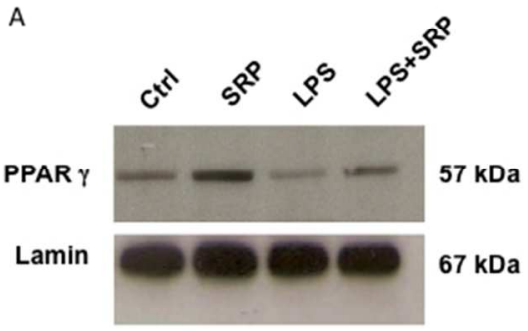

B

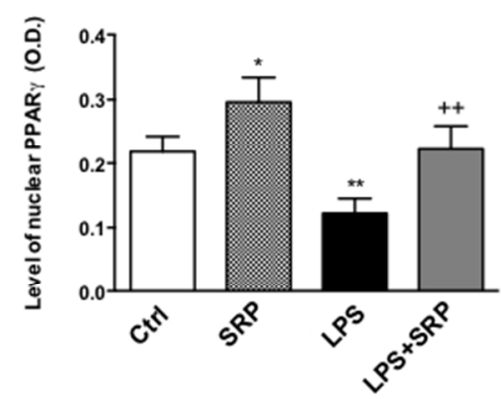

C

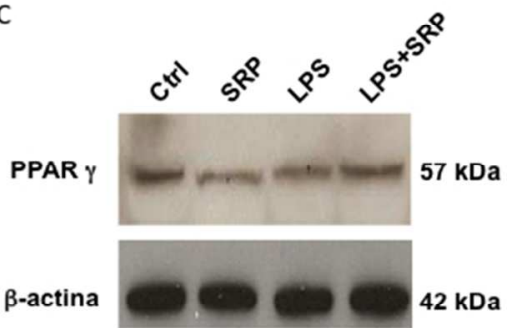

D

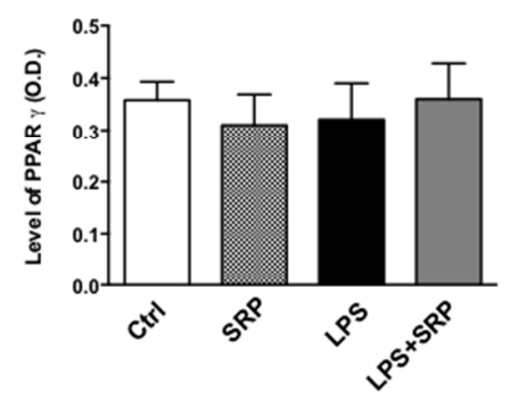

Nuclear PPARy protein expression of BV2 microglial cell line following a $90 \mathrm{~min}$. exposure to supplement rich in PUFas (SRP) $(10 \mu \mathrm{g} / \mathrm{mL})$, LPS $(1 \mu \mathrm{g} / \mathrm{mL})$, LPS $(1 \mu \mathrm{g} / \mathrm{mL})+$ SRP $(10 \mu \mathrm{g} / \mathrm{ml})$ or not-treated cells. (A) Representative western blots of five independent experiments. (B) Densitometric analysis of nuclear protein levels of PPARY after incubation with $10 \mu \mathrm{g} / \mathrm{mL}$ of SRP for $90 \mathrm{~min}$. in presence or not of LPS $1 \mu \mathrm{g} / \mathrm{mL}$. The values were normalized to the protein loading control, lamin and the results are means \pm SD of five independent experiments. ${ }^{*} \mathrm{P}<0.05$ and ${ }^{*} * \mathrm{P}<0.01$ vs not-treated cells $(\mathrm{Ctrl}) ;++\mathrm{P}<0.01$ vs LPS using oneway ANOVA with Tukey's as post test.

(C) Representative western blots analyses and densitometric analysis (D) of PPARY protein levels of BV2 microglial cell lysate after incubation with LPS $1 \mu \mathrm{g} / \mathrm{mL}$, with $10 \mu \mathrm{g} / \mathrm{mL}$ of SRP in presence or not of LPS (1 $\mu \mathrm{g} / \mathrm{mL}$ ) for $24 \mathrm{~h}$ and in no treated cells (Ctrl). The results are representative of four independent experiments.

$254 \times 190 \mathrm{~mm}(72 \times 72$ DPI $)$ 
Representative western blots analyses of PPARY $1 / 2$ protein levels in cerebral cortex of rats fed for 1 months with $2 \mathrm{~g} / \mathrm{rat} / \mathrm{day}$ of supplement rich in PUFAs (SRP) or fed with $2 \mathrm{~g} / \mathrm{rat} / \mathrm{day}$ of olive oil fed group (OOG). (A)

The results are representative of four independent experiments. (B) Densitometric analyses of cerebral protein levels of PPARY1/2. The values were normalized to the protein loading control, $\beta$-actin and the results are means \pm SD of five independent experiments. ${ }^{* * * P}<0.01$ vs olive oil fed group (OOG) using paired t-test.

$254 \times 190 \mathrm{~mm}(72 \times 72 \mathrm{DPI})$ 


\section{Figure captions}

\section{Figure 1. Cell viability of BV2 microglial cell line.}

Cell viability of BV2 microglial cell line after exposure to different concentrations of supplement rich in PUFAs (SRP) and LPS. (A) Effects of $24 \mathrm{~h}$ exposure to different concentrations of SRP on BV2 microglial cell line monitored by the MTS assay. Only the highest concentration of SRP decreased significantly the BV2 cell viability compared to not-treated cells: ${ }^{* * *} \mathrm{P}<0.001$ vs Ctrl using one-way ANOVA with Dunnett's as post test. (B) Effects of the supplement rich in PUFAs (SRP) on LPS-induced cytotoxicity on BV2 microglial cell line $\left({ }^{++} \mathrm{P}<0.01\right.$ vs $\mathrm{Ctrl}$, using one-way ANOVA with Tukey's as post test). SRP significantly decreased the BV2-cytotoxicyty elicited by LPS at all the concentrations tested. Values represent means \pm SD from three different experiments $(\mathrm{n}=6) .{ }^{*} \mathrm{P}<0.05,{ }^{* *} \mathrm{P}<0.01,{ }^{* * *} \mathrm{P}<0.001$ vs LPS using one-way ANOVA with Tukey's as post test.

Figure 2. ROS formation in LPS-activated BV2 microglial cell line.

ROS formation in LPS-activated BV2 microglial cell line as measured by Cell-ROX assay after 24 $\mathrm{h}$ of exposure in presence or not to different concentrations of supplement rich in PUFAs (SRP). Results are expressed as median fluorescence intensity (MFI). LPS treatment significantly increased the MFI compared to not-treated cells $\left({ }^{+++} \mathrm{P}<0.001\right.$ vs Ctrl, using one-way ANOVA with Tukey's as post test). Co-treatment of BV2 microglial cells with LPS and different concentrations of SRP significantly reduced the level of ROS in LPS-activated BV2 cell line. Data shown are means \pm SD of three independent experiments $(\mathrm{n}=6) .{ }^{* *} \mathrm{P}<0.01$, and ${ }^{* * *} \mathrm{P}<0.001$ vs LPS using one-way ANOVA with Tukey's as post test.

\section{Figure 3. NO production in LPS-activated BV2 microglial cell line.}

Effect of supplement rich in PUFAs (SRP) on LPS-activated BV2 microglial cell line nitrite levels as measured by the absorbance at $\lambda 540 \mathrm{~nm}$. BV2 microglial cell line treatment with LPS of for $24 \mathrm{~h}$ resulted in a significant increase of nitrite levels compared to the not-treated cells referred as control $\left({ }^{+++} \mathrm{P}<0.001\right.$ vs Ctrl, using one-way ANOVA with Tukey's as post test). Co-administration of LPS 
and SRP at different concentrations on BV2 microglial cells significantly reduced LPS-activated BV2 nitrite levels: ${ }^{*} \mathrm{P}<0.05,{ }^{* * *} \mathrm{P}<0.001$ vs LPS using one-way ANOVA with Tukey's as post test. Data shown are means \pm SD of three independent experiments $(n=5)$.

\section{Figure 4. Protein expression of BV2 microglial cell line.}

Nuclear PPAR $\gamma$ protein expression of BV2 microglial cell line following a 90 min. exposure to supplement rich in PUFas (SRP) $(10 \mu \mathrm{g} / \mathrm{mL})$, LPS $(1 \mu \mathrm{g} / \mathrm{mL})$, LPS $(1 \mu \mathrm{g} / \mathrm{mL})+\mathrm{SRP}(10 \mu \mathrm{g} / \mathrm{ml})$ or not-treated cells. (A) Representative western blots of five independent experiments. (B) Densitometric analysis of nuclear protein levels of PPAR $\gamma$ after incubation with $10 \mu \mathrm{g} / \mathrm{mL}$ of SRP for $90 \mathrm{~min}$. in presence or not of LPS $1 \mu \mathrm{g} / \mathrm{mL}$. The values were normalized to the protein loading control, lamin and the results are means $\pm \mathrm{SD}$ of five independent experiments. ${ }^{*} \mathrm{P}<0.05$ and ${ }^{* *} \mathrm{P}<$ 0.01 vs not-treated cells $(\mathrm{Ctrl}) ;{ }^{++} \mathrm{P}<0.01$ vs LPS using one-way ANOVA with Tukey's as post test. (C) Representative western blots analyses and densitometric analysis (D) of PPAR $\gamma$ protein levels of BV2 microglial cell lysate after incubation with LPS $1 \mu \mathrm{g} / \mathrm{mL}$, with $10 \mu \mathrm{g} / \mathrm{mL}$ of SRP in presence or not of LPS $(1 \mu \mathrm{g} / \mathrm{mL})$ for $24 \mathrm{~h}$ and in no treated cells (Ctrl). The results are representative of four independent experiments.

\section{Figure 5. Western blots of PPAR $\gamma$ protein levels in cerebral cortex of rats.}

Representative western blots analyses of PPAR $\gamma 1 / 2$ protein levels in cerebral cortex of rats fed for 1 months with $2 \mathrm{~g} /$ rat/day of supplement rich in PUFAs (SRP) or fed with 2g/rat/day of olive oil fed group (OOG). (A) The results are representative of four independent experiments. (B) Densitometric analyses of cerebral protein levels of PPAR $\gamma 1 / 2$. The values were normalized to the protein loading control, $\beta$-actin and the results are means \pm SD of five independent experiments. ${ }^{* * *} \mathrm{P}<0.01$ vs olive oil fed group (OOG) using paired t-test. 